\title{
A rare case of primary umbilical endometriosis in a nulliparous female confirmed on imaging and histopathology: Case report
}

\author{
Mohi J.K ${ }^{1}$, Singh $\mathbf{J}^{2}$, Kaur $\mathbf{A}^{3}$, Haq $\mathbf{S}^{4}$ \\ ${ }^{1}$ Dr. Jaswinder Kaur Mohi, Associate Professor, Radiology Department GMC Patiala, Punjab, India, ${ }^{2}$ Dr. Jasvir Singh, \\ Junior Resident, Radiology, ${ }^{3}$ Dr. Amarjit Kaur, Professor, Radiology Department, ${ }^{4}$ Dr. Samrin Haq, Junior Resident, \\ Radiology Department, Dr. Navkiran Kaur, Professor and Head Of Radiology Department, GMC Patiala, Punjab, India.
}

Address for Correspondence: Dr. Jasvir Singh, Email: jasvirsingh011789@ gmail.com

\begin{abstract}
Endometriosis is a common gynaecological condition, the pelvis being the most common site. Extrapelvic sites including intestinal tract, urinary tract, omentum, thorax, surgical scars and umbilicus are less common sites and are difficult to diagnose. Majority of extrapelvic cases occur at surgical scar sites. Occurrence of umbilical endometriosis in a patient without any previous surgical history is a very rare condition. So, we are going to report the case of a primary umbilical endometriosis in a 40 years old nulliparous female presented with complaints of pain abdomen associated with bleeding per vaginum and cyclical bleeding from umbilical region since 2 months. This paper summarises the topic of umbilical endometriosis and discusses the radiological and clinical implication of this unusual condition.
\end{abstract}

Key-words: Cyclical pain; Multiple uterine fibroids; Endometriosis; Fine needle aspiration.

\section{Introduction}

Primary endometriosis is a rare condition. Very few cases have been reported. Spontaneous or primary (i.e. not secondary to prior surgery) umbilical endometriosis was first described by Villar in 1886 [1]. Deposits of endometriosis occur frequently anywhere in the pelvis including vulva, vagina, cervix, ovaries, pelvic peritoneum, and less commonly (12\%) in the extrapelvic sites including intestinal tract, urinary tract, peritoneum, omentum, lung, thoracic cage, surgical scars, abdominal wall, inguinal region and umbilicus. The majority of the reported cases occurred in gynecologically induced abdominal or pelvic scars, including cesarean section and hysterectomy [2-4]. The navel is the most common site of cutaneous endometriosis, occurring between $0.5 \%$ and $1.2 \%$ of all cases of endometriosis [5].

\section{Case History}

40 years old nulliparous patient came to our hospital with complaints of pain abdomen associated with bleeding per vaginum and cyclical bleeding from the umbilical region since 2 months. On detailed history asked by gynaecology resident history of dyspareunia was present. However, no postcoital bleeding was present. Moreover, patient gives history of primary infertility. Patient was referred to radiology department for ultrasonography. On ultrasonography, uterus is enlarged and heterogenous in echo pattern. Multiple fibroids with bilateral adnexal cystic lesions filled with low level echoes were found. A hypoechoic nodule measuring $\sim 1.6 \times 1.2 \mathrm{~cm}$ was seen in the region of umbilicus which on color doppler shows minimal vascularity. MRI was also done for detailed evaluation. On T1WI the cutaneous lesion was hypo to slightly hyperintense and hypointense on T2WI. On contrast administration, intense enhancement is seen within this lesion. Also, hypointense masses are seen within the uterus. Ultrasonography guided fine needle aspiration of this nodule was done, which was confirmed to be umbilical endometriosis. There was no history of previous laparotomy, so final diagnosis of primary umblical endometriosis was made.

Manuscript received $24^{\text {th }}$ June 2016

Reviewed: $4^{\text {th }}$ July 2016

Author Corrected: $16^{\text {th }}$ July 2016

Accepted for Publication $30^{\text {th }}$ July 2016 
Other investigations- Hematology: Complete blood count, renal function tests, liver function tests, serum calcium levels were within normal limits. Urine routine and microscopy: traces of albumin 1-2 RBCs.
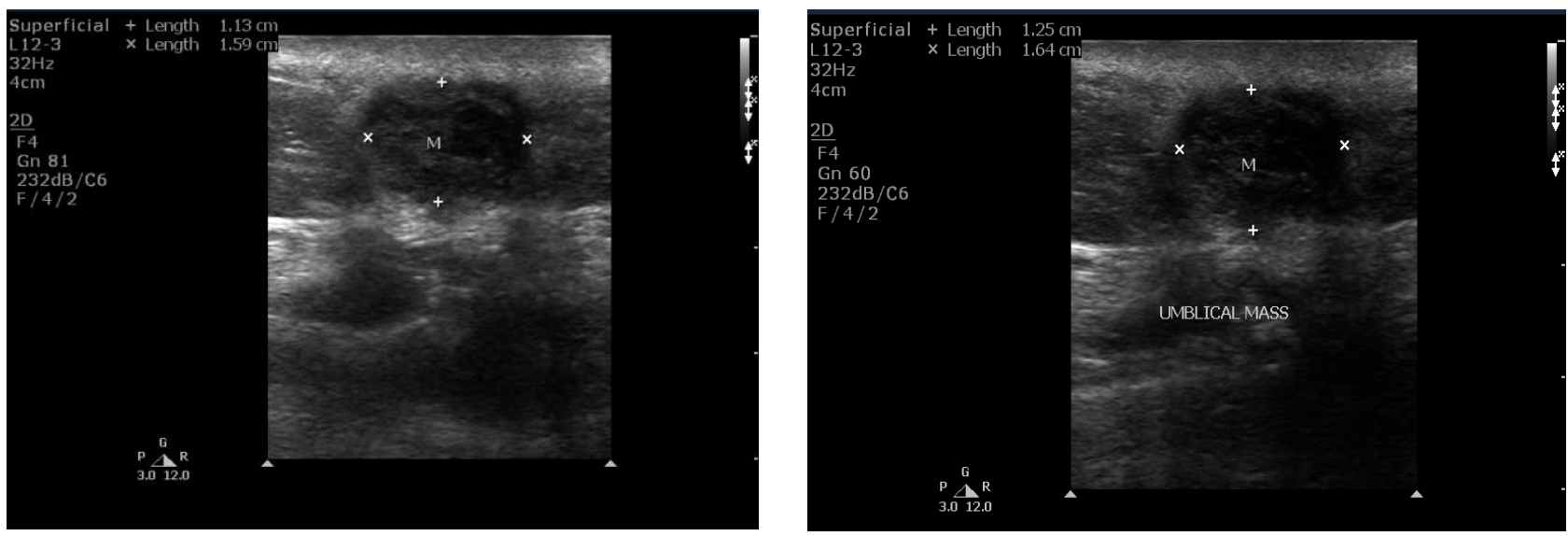

Figure-1: Ultrasonography of the umbilical region; A hypoechoic mass is seen in the region of umbilicus

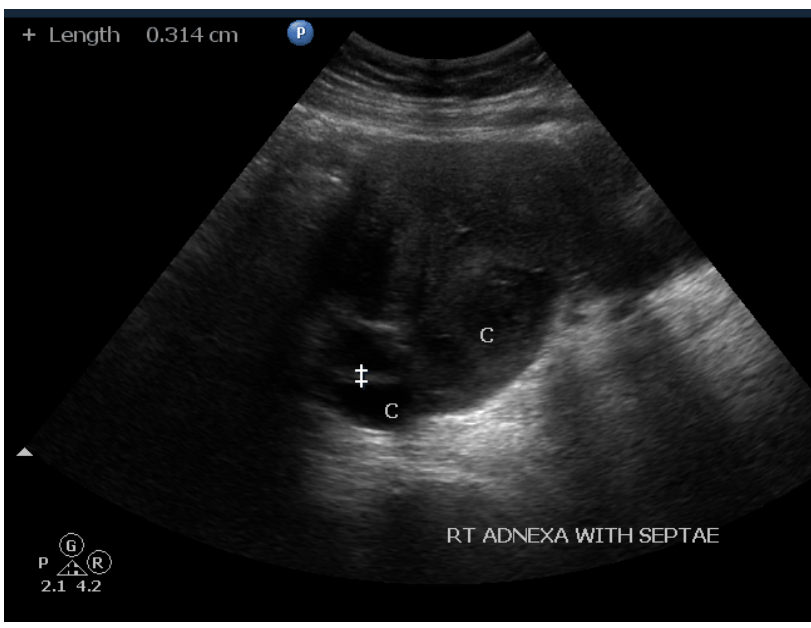

Figure-2:A. Ultrasonography picture of the bilateral adenexal region showing cystic lesions with echoes and septa

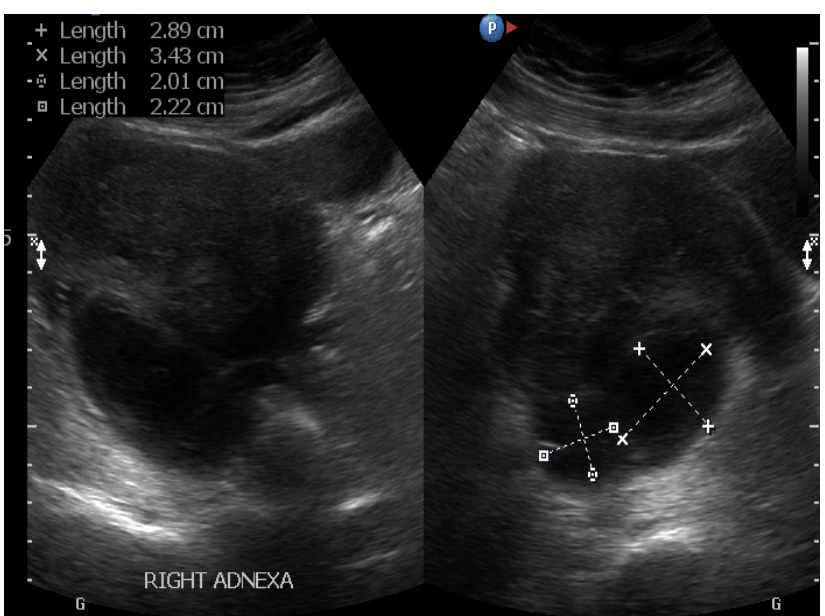

Figure-2:B. Ultrasonography picture of the bilateral adenexal region showing cystic lesions with echoes and septa

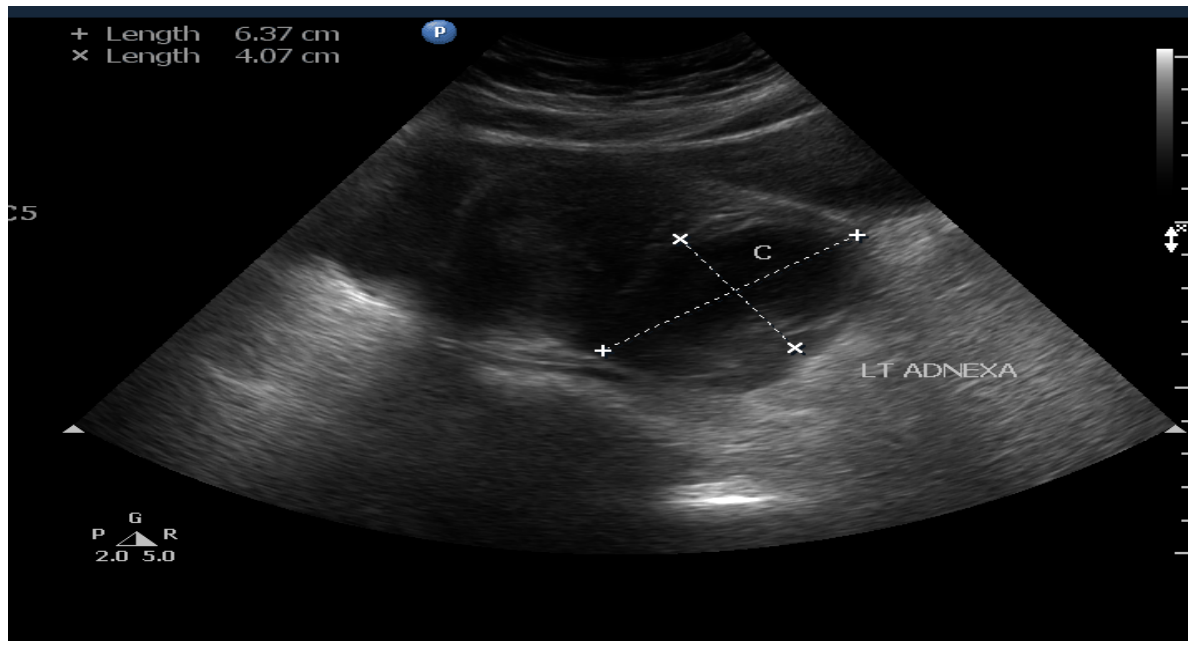

Figure-2:C. Ultrasonography picture of the bilateral adenexal region showing cystic lesions with echoes and septae 

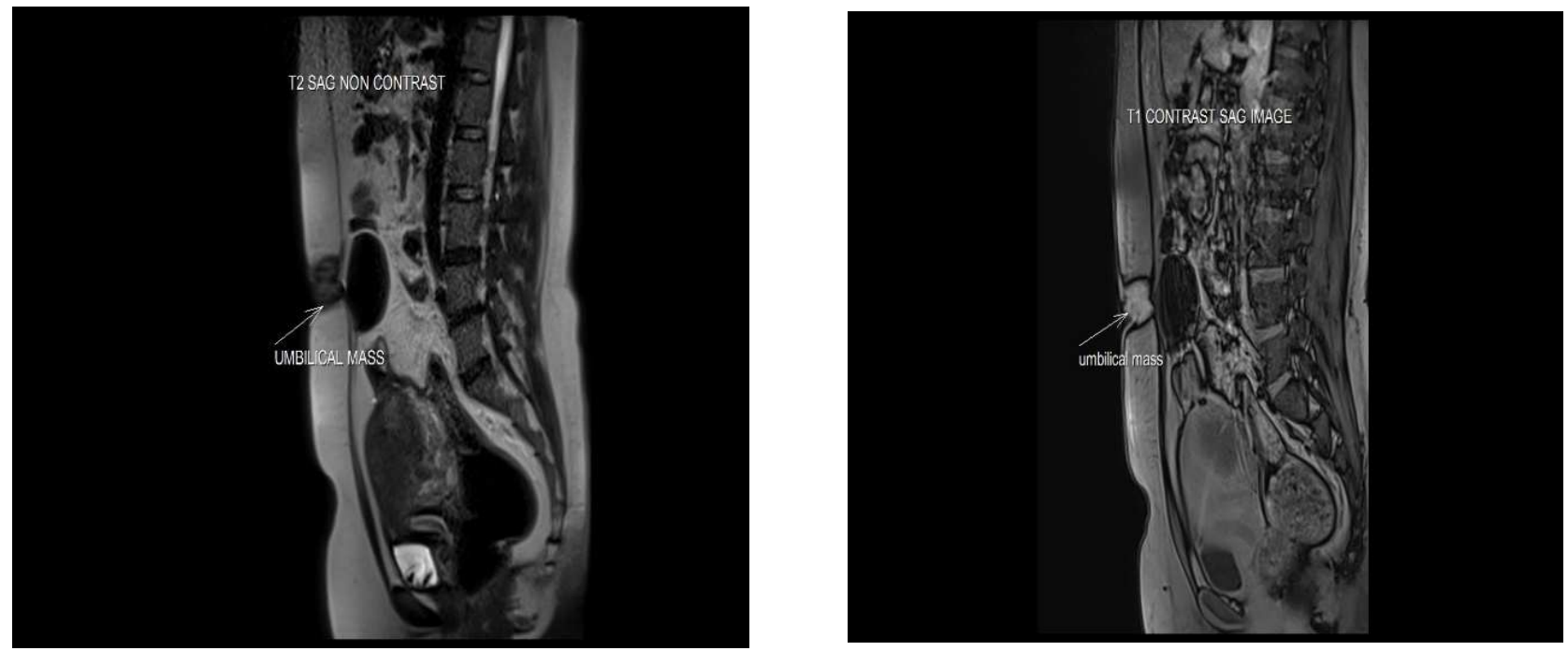

Figure-3: Saggital T2WI showing a hypointense mass in the region of umbilicus and intense enhancement is seen in the mass on $\mathrm{T} 1$ contrast weighted imaging.
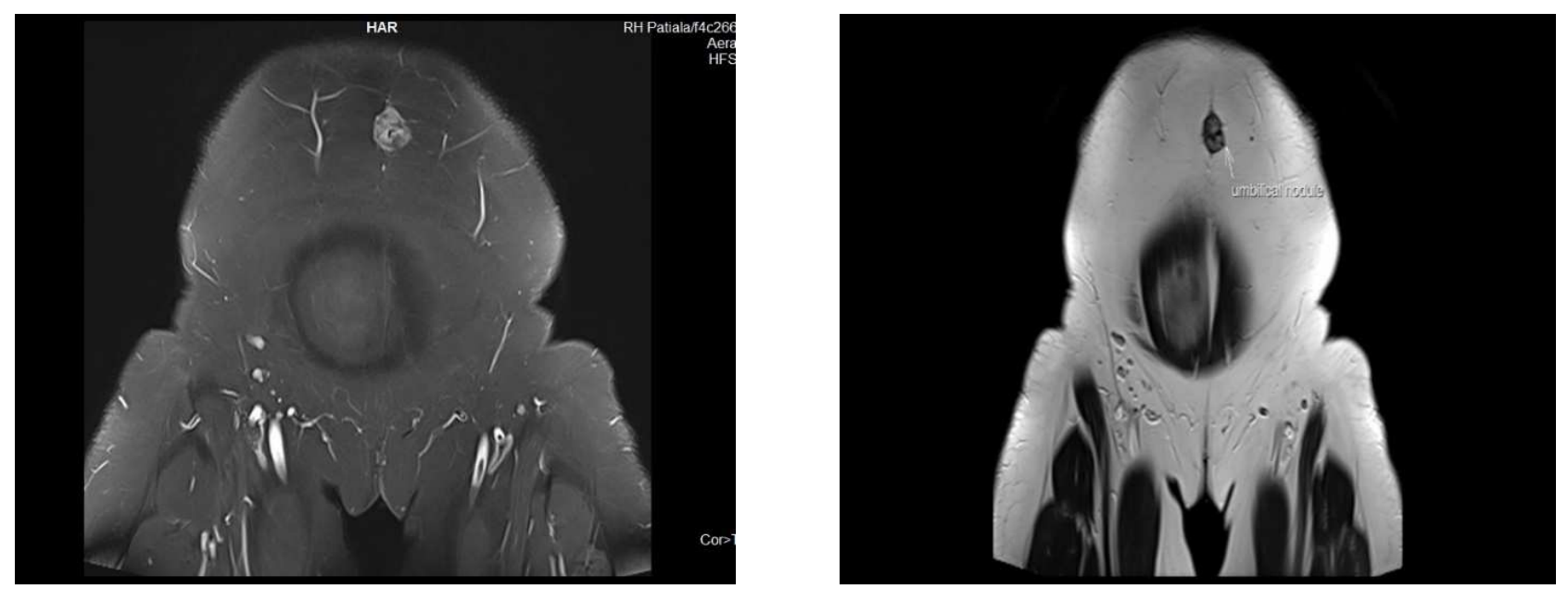

Figure-4: Coronal $\mathrm{T} 1$ contrast and $\mathrm{T} 2$ weighted mri images showing the same.
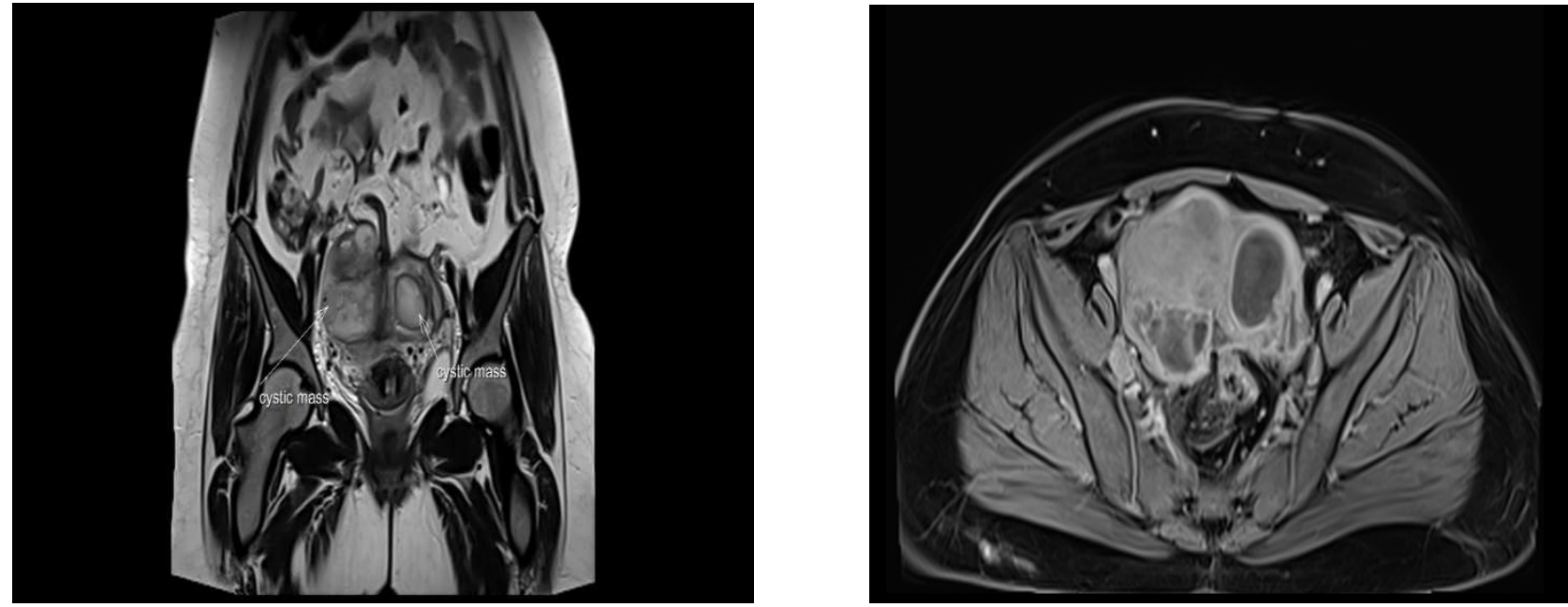

Figure-5: Coronal and axial MRI image showing bilateral hypointense adenexal lesions 


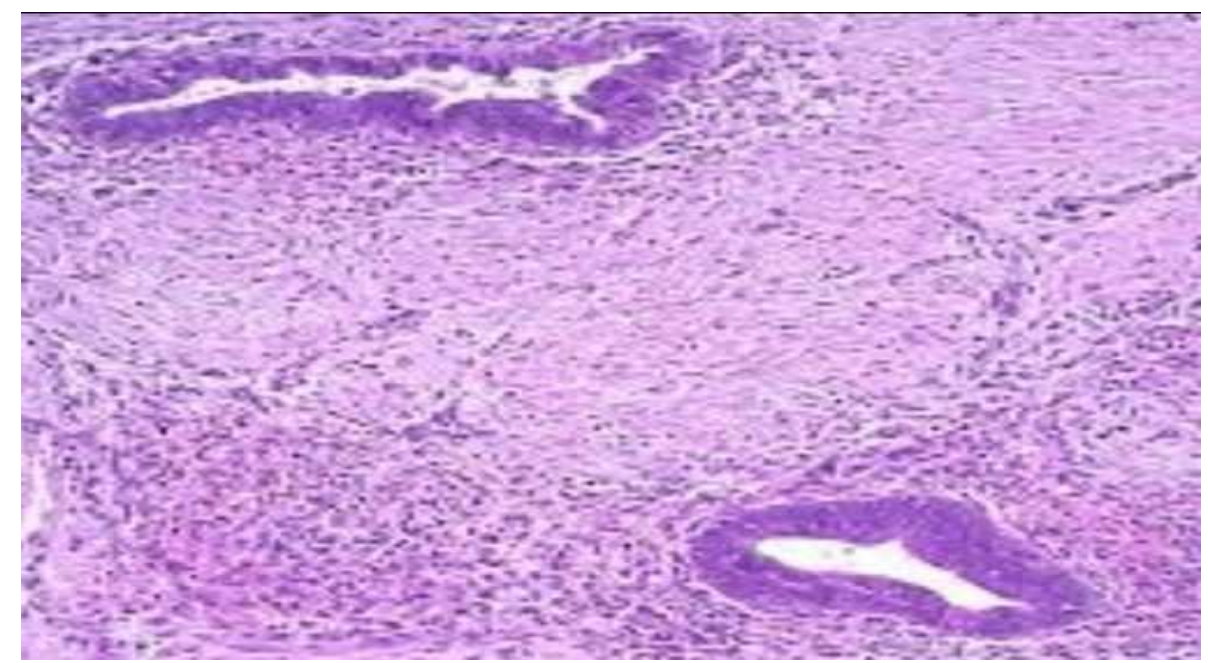

Figure 6 : MRI coronal and sagittal images (VIBE sequences) showing the cutaneous lesion conforming to imaging features of endometriosis

Cytological findings: Aspirated material from umbilical region later on histopathology shows endometrial glands ( lined by columnar epithelium with crowed nuclei) and stroma which further confirms the same.

\section{Discussion}

Abdominal wall endometriosis (AWE) is defined as endometrial tissue that is superficial to the peritoneum. AWE is often difficult to diagnose, mimicking a broad spectrum of diseases. Cutaneous endometriosis accounts for less than $5.5 \%$ of all endometriosis cases [3]. Patients can present weeks to years after surgery with a palpable mass or focal pain associated with menses [3]. If umbilical endometriosis coexists with pelvic endometriosis then, the theory of lymphatic and hematogenous transplantation is favored. However, it is believed that the disease might arise through metaplasia of urachus remnants in case of isolated umbilical endometriosis [4].

These patients commonly present with a brownish or bluish painful umbilical nodule, as noted in our patient. A few series have reported bleeding from the nodule [5]. However, only $75 \%$ of patients have their symptoms associated with the menstrual cycle. Because characteristic symptoms are not always present, clinical diagnosis of umbilical endometriosis can be difficult. So, possibility of umbilical endometriosis must be kept in mind along with other differential diagnosis that includes abscess, hematoma, hernia, sebaceous cyst, lipoma, hemangioma, and malignant tumor [4,7]. Symptoms associated with endometriosis include infertility and cyclical pain. Infertility, with or without pelvic pain, may be the presenting complaint in women with endometriosis. It is estimated that $30 \%-50 \%$ of women with endometriosis are infertile, and $20 \%$ of infertile women have endometriosis. [8] The most widely accepted pathogenesis of secondary endometriosis is the iatrogenic implantation of endometrial cells as a result of surgery, commonly laparoscopic procedures. However, the pathogenesis of primary endometriosis remains uncertain. Theories suggested include the implantation of cells through sanguineous or lymphatic spread, or differentiation from coelomic pluripotent cells in the skin [9]. Less than $30 \%$ of cutaneous endometriosis appears in the absence of a prior surgical history and is termed spontaneous (primary) cutaneous endometriosis.Of these cases, the most common site involved is the umbilicus [10].

Key Messages: A rare condition of umbilical endometriosis in a patient without any history of laparotomy. Now, presented with complaints of bleeding per vaginum and cyclical bleeding from umbilical region since 2 months

\section{Conclusion}

Making a diagnosis of primary umblical endometriosis is difficult and other causes of umbilical lesions should be ruled out. Surgical excision is the standard treatment of choice.

Funding: Nil, Conflict of interest: None initiated, Permission from IRB: Yes 


\section{References}

1. Victory R, Diamond MP, Johns DA. Villar's nodule: a case report and systematic literature review of endometriosis externa of the umbilicus. J Minim Invasive Gynecol. 2007 Jan - Feb; 14 (1): $23-32$.

2. Agarwal A, Fong YF. Cutaneous endometriosis. Singapore Med J. 2008 Sep;49(9):704-9.

3. Kyamidis K., Lora V., Kanitakis J. Spontaneous cutaneous umbilical endometriosis: report of a new case with immunohistochemical study and literature review. Dermatol Online J. 2011;17:5.

4. Teh WT, Vollenhoven B, Harris PI. Umbilical endometriosis, a pathology that a gynecologist may encounter when inserting the Veres needle. Fertil Steril. 2006 Dec;86(6):1764.e1-2. Epub 2006 Oct 30.

5. Molderez CM, Wouters KB, Bergmans GB, Michiels GK. Umbilical discharge: a review of 22 cases. Acta Chir Belg. 1995 May-Jun;95(3):166-9.
6. Fernández-Aceñero MJ, Córdova S. Cutaneous endometriosis: review of 15 cases diagnosed at a single institution. Arch Gynecol Obstet. 2011 May;283 (5): 1041-4. doi: 10.1007/s00404-010-1484-3. Epub 2010 Apr 27.

7. Zwas FR, Lyon DT. Endometriosis. An important condition in clinical gastroenterology. Dig Dis Sci. 1991 Mar;36(3):353-64.

8. Eskenazi B, Warner ML. Epidemiology of endometriosis. Obstet Gynecol Clin North Am. 1997 Jun;24(2):235-58.

9. Frischknecht F, Raio L, Fleischmann A, Dreher E, Lüscher KP, Mueller MD. Umbilical endometriosis. Surg Endosc. 2004 Feb;18(2):347.

10. Fernández-Aceñero MJ, Córdova S. Cutaneous endometriosis: review of 15 cases diagnosed at a single institution. Arch Gynecol Obstet. 2011 May;283 (5):1041-4. doi: 10.1007/s00404-010-1484-3. Epub 2010 Apr 27.

\section{How to cite this article?}

Mohi J.K, Singh J, Kaur A, Haq S. A rare case of primary umbilical endometriosis in a nulliparous female confirmed on imaging and histopathology: Case report. Int J Med Res Rev 2016;4(8):1415-1419.doi:10.17511/ijmrr.2016.i08.21. 